\title{
ИНТЕРФЕРОН-ТАЧ И ФОРМИРОВАНИЕ БЕРЕМЕННОСТИ У КОРОВ
}

\author{
С.В. ШАБУНИН 1 , А.Г. НЕЖДАНОВ1, В.И. МИХАЛЕВ1, Н.В. ПАСЬКО1,
} В.А. ПРОКУЛЕВИЧ ${ }^{2}$, М.И. ПОТАПОВИЧ ${ }^{2}$, В.А. ГРИЦЮК ${ }^{3}$, И.В. ВОЛКОВА 1

Формирование беременности и развитие эмбриона и плода у коров обеспечивается со-
гласованным действием стероидных и пептидных гормонов и интерферонов. К особому классу
последних относится интерферон-tau (INFT), синтезируемый трофобластными клетками эмбрио-
на. INFT ответствен за сохранение прогестеронсинтезирующей функци желтого тела яичника и
имплантацию эмбриона. В настоящей работе мы впервые показали патогенетическую значимость
INFT в нарушении эмбрионального развития и оценили биологическую и клиническую эффектив-
ность бычьего рекомбинантного INFT при его назначении коровам после искусственного осеме-
нения. Нашей целью было изучение динамики содержания в крови у коров интеферона-tаu и
прогестерона (Р) в ранний период гестации и выявление возможностей использования бычьего
рекомбинантного INFT в качестве средства профилактики эмбриональных потерь и повышения
результативности осеменения. Рекомбинантный INFT был получен в Белорусском государственном университете. Исследования выполняли в 2017 году в условиях ООО «СП Вязноватовка» (Нижнедевицкий р-н, Воронежская обл.) на коровах (Bos taurus taurus) черно-пестрой породы (105 гол.) 4-7-летнего возраста. Содержание INFT и $P_{4}$ определяли на 7-e, 14-e, 21-е и 35-е сут после искусственного осеменения при физиологическом формировании эмбриона $(n=15)$ и при его гибели $(n=3)$ методом ИФА с использованием тест-систем Bovine Interferon-Tau Elisa Kit (США) и Иммуно-Фа-ПГ (Россия). Чувствительность анализа INFT составляла 2,9 пг/мл, $\mathbf{P}_{4}-$ 0,4 нмоль/л. Одновременно в крови коров определяли фагоцитарную активность лейкоцитов, содержание сывороточных иммуноглобулинов и бактерицидную активность сыворотки крови (БАСК). О наличии или отсутствии эмбриона в матке судили по концентрации в сыворотке прогестерона на 21-е и 35-е сут и на основании двукратного УЗИ на 35-е и 50-е сут. Эффективность разных доз и схем применения рекомбинантного интерферона для повышения результативности осеменения и профилактики синдрома задержания развития оценивали на 87 коровах. Препарат INFT вводили парэнтерально 1-, 3-и 5-кратно в дозах по 5 и 10 мл с 12-х по 16-е сут после осеменения. В качестве контроля использовали группу интактных животных и группу с введением пролонгированного препарата прогестерона - прогестамага. C 7-x по 14-е сут формирования эмбриона концентрация INFT в сыворотке крови коров возросла на 23,2 \%, а к 35-м сут снизилась на $30,8 \%$, содержание $P_{4}$ увеличилось в 32 раза. При гибели эмбриона концентрация INFT на 14-е сут была ниже на $7,7 \%$, а на 35 -е сут - на $25,2 \%$. Количество Р 4 оказалось ниже на 21-е сут на 26,5 \%, на 35-е сут - в 9,3 раза. Это дает основание заключить, что гипоинтерферонемия и сопутствующая ей гипопрогестеронемия становятся одними из причин задержки развития и гибели эмбрионов на ранних этапах беременности. Оптимальным режимом назначения рекомбинантного INFT для формирования беременности у коров было 3-кратное парэнтеральное введение в дозе 5 мл на 12-е, 14-е и 16-е сут после осеменения. Результативность осеменения в сравнении с интактными животными повысилась с 38,9 до 75,0 \%, или на 36,1 \%, проявление синдрома задержки развития плода снизилось с 28,6 до $16,7 \%$, или на $11,9 \%$. Метрические показатели развивающихся эмбрионов на 28-30-е сут беременности превышали контроль на $32,2 \%$, на 60-65-е сут - на 55,3\%, масса телят при рождении - на 14,2 \%. Это происходило на фоне увеличения концентрации INFT в крови на 33,9\% и прогестерона в 2,3 раза. Прямое восполнение дефицита прогестерона у животных посредством введения прогестамага обеспечило повышение у них сохранности беременности на 33,1 \%. Показано также, что этот препарат оказывает на организм коров иммуномодулирующее действие. После его 3-кратного назначения фагоцитарная активность лимфоцитов возросла на $8,7 \%$, фагоцитарное число - на 35,1 \%, фагоцитарный индекс - на $25,1 \%$, БАСК увеличилась на $5,9 \%$, содержание иммуноглобулинов - на $14,3 \%$. Сделано заключение о целесообразности использования рекомбинантного INFT для повышения фертильности маточного поголовья крупного рогатого скота.

Ключевые слова: Bos taurus taurus, коровы, кровь, интерферон-tau, прогестерон, ранний эмбриогенез, эмбриональная гибель, фертильность.

Современные достижения биологической науки в области иммуноэндокринного контроля беременности у животных свидетельствуют, что внутриутробное формирование и развитие эмбриона и плода обеспечивается согласованным перекрывающимся действием прогестерона, соматотропина, плацентарного пролактина, кортизола, а также интерферонов, продуцируемых иммунокомпетентными клетками маточно-плацентарного 
комплекса (1-3). Продукция и действие последних составляет важнейший механизм материнско-плодных взаимоотношений (4-5).

Интеферон-tau (INFT) - особый класс интерферонов, имеющий непосредственное отношение к формированию беременности, обладающий общим со всеми интерферонами свойством и обеспечивающий имплантацию и элонгацию эмбриона (6-8). Он впервые обнаружен в 1982 году у овец (9-10) и несколько позже у коров и коз. INFT вырабатывается моноядерными трофобластными клетками эмбриона с первых суток беременности, достигает максимального содержания в период имплантации и способствует включению в этот процесс всех механизмов принятия зародыша материнским организмом (11-13). В первую очередь он обеспечивает сохранение и продление прогестероносинтезирующей функции желтого тела яичника. Механизм его антилютеолитического действия связан с блокадой в эндометрии рецепторов окситоцина и эстрогенов и ингибированием продукции лютеолитического простагландина $\mathrm{F}_{2} \alpha\left(\mathrm{PGF}_{2} \alpha\right)$. Кроме того, INFT ингибирует ключевые лютеолитические гены, индуцируемые $\mathrm{PGF}_{2} \alpha$, в самом желтом теле (14). Обладая опосредованным и прямым антилютеотическим действием, он увеличивает продолжительность жизни лютеоцитов на ранних сроках беременности и активный синтез прогестерона, обеспечивающего активную секреторную реакцию эндометрия и питание зародыша. Показано также (15), что INFT стимулирует экспрессию мРНК интерлейкина IL-8 внутри желтого тела, активирует миграцию в него нейтрофилов и повышает тем самым секрецию лютеоцитами прогестерона (16). INFT оказывает прямое влияние на синтез других цитокинов (INF- $\gamma$, IL-2, IL-4) (17-19), обладает антивирусным действием и выступает в качестве одного из посредников индукции противовоспалительной реакции в матке коров. Эта реакция на присутствие эмбриона проявляется уже в первые 4 сут его жизни в матке $(20,21)$.

В совокупности биологическое действие INFT в организме животных направлено на создание физиологически необходимых условий для внутриутробного развития эмбриона и плода. Его недостаточная продукция приводит к потере беременности на ранних сроках гестации. Следует отметить, что в отечественной литературе публикации по этому весьма актуальному и перспективному направлению научных исследований практически отсутствуют.

В настоящей работе мы впервые определили содержание в крови у коров INFT и $\mathrm{P}_{4}$ в период эмбриогенеза при физиологическом формировании эмбриона, задержке его развития и гибели. Показана патогенетическая значимость INFT в нарушении эмбрионального развития. Впервые оценена биологическая и клиническая эффективность бычьего рекомбинантного INFT при его назначении коровам после искусственного осеменения.

Нашей целью было изучение динамики содержания в крови у коров интеферона-tau и прогестерона в ранний период гестации и выявление возможностей использования бычьего рекомбинантного INFT в качестве средства профилактики эмбриональных потерь и повышения результативности осеменения.

Методика. Исследования были выполнены в 2017 году в условиях ООО «СП Вязноватовка» (Нижнедевицкий р-н, Воронежская обл.) при привязной технологии содержания на коровах (Bos taurus taurus) чернопестрой породы (105 гол.) 4-7-летнего возраста со среднегодовой молочной продуктивностью 6,5-7,6 тыс. кг. Кормление животных осуществлялось по нормам Всероссийского НИИ животноводства.

В первой серии опытов на 18 коровах исследовали динамику со- 
держания в сыворотке крови интеферона-tau и прогестерона при физиологическом формировании эмбриона и при его гибели. Их содержание определяли методом иммуноферментного анализа с использованием тестсистем Bovine interferon-Tau Elisa Kit («Clod Clone Corp.», США) и Иммуно-Фа-ПГ («Иммунотех», Россия) на 7-е, 14-е, 21-е и 35-е сут после искусственного осеменения животных криоконсервированной спермой. Кровь получали из подхвостовой вены. Чувствительность анализа INFT составляла менее 2,9 пг/мл, прогестерона $\left(\mathrm{P}_{4}\right)-0,4$ нм/л. О наличии или отсутствии эмбриона в матке судили по концентрации в сыворотке крови прогестерона на 21-е и 35-е сут и на основании двукратного УЗИ на 35-е и 50-е сут. Для проведения УЗИ использовали ультразвуковой сканер EasiScan-3 («BCF Technology», Великобритания) с линейным зондом 7,5 МГц.

Во второй серии опытов, выполненных на 87 коровах, изучили эффективность применения бычьего рекомбинантного интерферона-tau для профилактики эмбриональной смертности и повышения результативности осеменения. Интеферон-tau получен в Белорусском государственном университете. Последовательность гена бычьего интерферона-tau (INFT), оптимизированная для экспрессии в клетках Escherichia coli, была сконструирована с помощью программы DNAStar (https://www.dnastar.com/software/). Синтез оптимизированной последовательности выполнен компанией «Integrated DNA Technologies» (США), последовательность клонирована в составе вектора pIDTSmart по сайтам рестрикции Nde I и Eco RI. После этого ген бычьего INFT был переклонирован в составе экспериссионного вектора pET24b(+) по тем же сайтам рестрикции. Для визуализации результатов использовали систему гель-документации Fusion FX («Vilber Lourmat», Франция). Кальциевую трансформацию, рестрикционный анализ, лигирование проводили в соответствии со стандартными протоколами (22). Далее рекомбинантной плазмидой рЕT24-cow INFT трансформировали штамм E. coli BL21CodonPlus(DE3)-RIPL, в клетках которого осуществляли индуцибельную экспрессию гена бычьего INFT. Бактерии $E$. coli BL21CodonPlus(DE3)-RIPL-pET24-cow INFT выращивали в биореакторе Biotron F15L («Biotron», Корея) объемом 10 л при $37^{\circ} \mathrm{C}$ в течение 7 ч в среде LB с добавлением канамицина и хлорамфеникола. Затем проводили индукцию, добавляя изопропил- $\beta-\mathrm{D}-1-$ тиогалактопиранозида (ИПТГ, IPTG), продолжали культивирование в течение еще 4 ч, после чего клетки собирали центрифугированием на проточной центрифуге Avanti J30I («Beckman Coulter», США), разрушали на проточном гомогенизаторе Panda Plus 2000 («Gea», Италия) под давлением 1000 бар и разделяли клеточный гомогенат центрифугированием.

Тельца включения, содержащие INFT, отмывали и солюбилизировали в буфере с гидрохлоридом гуанидина. После этого проводили рефолдинг INFT и очищали рекомбинантный белок хроматографически (обессоливание, ионообменная и эксклюзионная хроматография) на хроматографе среднего давления NGC Scout Plus («Bio-Rad», США). Чистота белка по данным ВЭЖХ (ВЭЖХ-хроматограф Ultimate 3000, «Thermo Fisher», США) и белкового электрофореза составила > $99 \%$, противовирусная активность - $1,02 \times 10^{9}$ МЕ/мг. Противовирусную активность измеряли на линии клеток MDBK с вирусом везикулярного стоматита, штамм Индиана.

В работе использовали ферменты и буферные системы фирмы «Thermo Scientific» (США). Плазмидную ДНК выделяли с помощью набора реагентов Nucleospin Plasmid («Macherey-Nagel», Германия), ДНК из агарозного геля - с использованием набора реагентов Nucleospin Gel and PCR Clean-up («Macherey-Nagel», Германия) согласно прилагаемым про- 
токолам. Электрофорез белков в полиакриламидном геле проводили по методике, описанной U.K. Laemmli (23).

Включенные в опыт животные были распределены на семь групп. Коров осеменяли замороженно-оттаянной спермой в дозе 0,25 мл, содержащей 15 млн спермиев с активным поступательным движением. Сперму вводили через цервикальный канал в полость тела матки во время проявления рефлекса неподвижности. Коровам из I группы $(n=18)$ препарат не назначали (отрицательный контроль). Животным из II группы $(n=25)$ на 5-е и 12-е сут после искусственного осеменения инъецировали препарат прогестамаг - прогестерон пролонгированного действия (ЗАО «Мосагроген», Россия) в дозе 2 мл (положительный контроль). Коровам III группы $(n=8)$ однократно на 12-е сут инъецировали бычий рекомбинантный INFT (OOO «НПУ ПроБиоТех», Беларусь) в дозе 5 мл, IV группы $(n=8)-$ INFT в дозе 10 мл, V группы $(n=8)$ - INFT в дозе 5 мл на 12-е и 14-е сут, VI группы $(n=8)$ - INFT в дозе 5 мл на 12-е, 14-е и 16-е сут, VII группы $(n=8)$ - INFT в дозе 10 мл ежедневно с 12-х по 16-е сут. Время инъекций интерферона было приурочено к периоду нидации и имплантации эмбриона (12-17-е сут).

Клиническую оценку эффективности экзогенного интерферона-tau и выбор оптимального варианта его назначения осуществляли по результатам УЗИ-диагностики беременности и метрическим показателям формирующихся эмбрионов на 28-30-е и 60-65-е сут развития. Перед постановкой опыта и при диагностировании беременности или бесплодия в крови у подопытных коров определяли содержание INFT, прогестерона, а также фагоцитарную активность лейкоцитов, бактерицидную активность сыворотки крови (БАСК) и количество в ней общих иммуноглобулинов в соответствии с методическими рекомендациями (24). При завершении беременности учитывали характер течения родов, послеродового периода у коров, а также массу тела новорожденных телят.

Полученные в эксперименте данные подвергали статистической обработке с использованием прикладной программы Statistica 8.0 («StatSoft Inc.», США). Результаты выражали как среднее арифметическое $(M)$ и стандартное отклонение $( \pm \mathrm{SD})$. Статистическую значимость определяли с использованием парного W-критерия Вилкоксона. Различия считали статистически значимыми при $\mathrm{p}<0,05$.

Результаты. В первой серии опытов физиологическое формирование эмбриона зарегистрировали у 15 коров, его гибель - у 3 животных. Установлено, что при формировании эмбриона концентрация в сыворотке

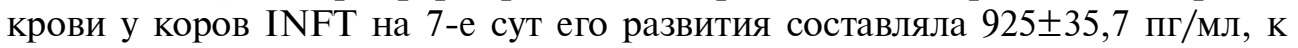
$14-$ м сут возрастала на 23,2 \% (р < 0,05), на 21-е снижалась на $13,7 \%$, а к 35-м - на 30,8 \% (р < 0,001) (табл. 1). По данным М. Kose с соавт. (25), содержание интерферон-tau в крови у жвачных животных достигает максимальных значений к 17-м сут беременности, а затем снижается на 2022-е сут. Концентрация $\mathrm{P}_{4}$ за этот период возрастала в 3,2 раза $(\mathrm{p}<0,001)$. Следовательно, пик продукции трофобластического интерферона у коров приходится на период имплантации зародыша, что обеспечивает высокую прогестерон-синтезирующую активность желтого тела, нормальное питание и формирование зародыша. При гибели эмбриона содержание INFT на 14-е сут составляло 1052 36,1 пг/мл, что было ниже, чем у здоровых животных, на 7,7 \%, а концентрация прогестерона на 21-е сут снижалась

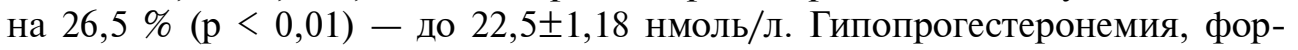
мирующаяся у животных, вызвала компенсаторное увеличение продукции INFT к 21-м сут: его концентрация повышалась в 1,32 раза $(\mathrm{p}<0,01)$ по 
сравнению со здоровыми коровами. Однако запоздалое по времени увеличение количества интерферона не обеспечивало пролонгацию функции желтого тела и сохранение формирующегося эмбриона. К моменту его гибели содержание INFT в крови снижалось до $679 \pm 31,4$ пг/мл, а прогесте-

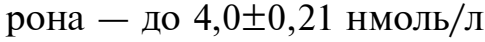

1. Концентрация интерферона-tau и прогестерона в сыворотке крови (Bos taurus taurus) коров черно-пестрой породы при физиологическом формировании эмбриона и его гибели $(M \pm \mathrm{SD}, \mathrm{CП}$ «Вязноватовка», Нижнедевицкий р-н, Воронежская обл., 2017 год)

\begin{tabular}{l|c|c|c|c}
\hline \multicolumn{1}{c}{ Физиологическое } & \multicolumn{4}{c}{ Срок после осеменения, сут } \\
\cline { 2 - 4 } \multicolumn{1}{c}{ состояние коров } & 7 -е & 14 -е & $21-\mathrm{e}$ & 35 -е \\
\hline \multirow{2}{*}{ Формирование беременности } & $925 \pm 35,7$ & $1140 \pm 54,2$ & $984 \pm 27,5$ & $800 \pm 33,4$ \\
Эмбриональная смертность & - & $1052 \pm 36,1$ & $1297 \pm 48,9^{*}$ & $679 \pm 31,4$ \\
\multicolumn{5}{c}{ Формирование беременности } \\
Эмбриональная смертность
\end{tabular}

Прямое восполнение дефицита прогестерона посредством парэнтерального введения прогестерон-содержащих препаратов обеспечило повышение сохранности беременности у таких животных в сравнении с интактными коровами на 33,1 \% (табл. 2). Эффективность назначения интерферона-tau зависела от дозы и кратности введения. Оптимальным было 3-кратное введение с 48-часовыми интервалами в дозе 5 мл (на 12-е, 14-е, 16-е сут после осеменения). При этом показатели сохранения беременности превысили таковые у животных из интактной группы на $36,1 \%$, а частота синдрома задержки развития эмбриона снизилась на $11,9 \%$. Увеличение дозы и кратности введения интерферона-tau не обеспечило улучшения клинического эффекта.

2. Результаты применения интерферона-tau для профилактики эмбриональной смертности и повышения результативности осеменения у коров (Bos taurus taurus) черно-пестрой породы (СП «Вязноватовка», Нижнедевицкий р-н, Воронежская обл., 2017 год)

\begin{tabular}{l|c|c|c|c}
\hline \multirow{2}{*}{ Группа } & Осеменено & \multicolumn{2}{|c|}{ Диагностирована беременность } & Синдром задержки раз- \\
\cline { 3 - 5 } & коров & число & $\%$ & вития плода, число/\% \\
\hline I (отрицательный контроль) & 18 & 7 & 38,9 & $2 / 28,6$ \\
II (положительный контроль) & 25 & 18 & 72,0 & $4 / 22,2$ \\
III & 8 & 3 & 37,5 & $1 / 33,3$ \\
IV & 8 & 5 & 62,5 & $1 / 20,0$ \\
V & 8 & 6 & 75,0 & $1 / 16,7$ \\
VI & 8 & 4 & 50,0 & $1 / 25,0$ \\
VII & 8 & 5 & 62,5 & $1 / 20,0$ \\
П р и м е ч а н и е. Описание групп см. в разделе «Методика». & & \\
\hline
\end{tabular}

У коров из V группы концентрация INFT в сыворотке крови с 12-х

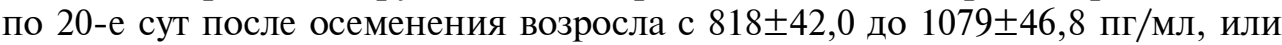

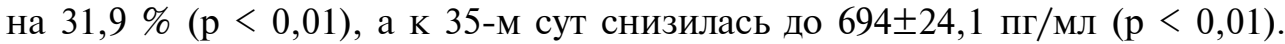
При этом содержание $\mathrm{P}_{4}$ в те же сроки возросло в 2,7 раза - с $17,1 \pm 1,16$ до $46,9 \pm 2,41$ нмоль/л (р $<0,001)$ и превосходило значение у интактных животных с физиологическим течением беременности на $25,7 \%(\mathrm{p}<0,01)$. Во II группе концентрация в сыворотке крови INFT возросла с 858 27,0 до $919 \pm 38,5$ пг/мл, или на 7,1 \%, тогда как содержание прогестерона увеличилось с $15,8 \pm 0,87$ до $41,8 \pm 2,64$ нмоль/л, или в 2,6 раза (p $<0,001)$. Следовательно, насыщение организма коров экзогенным прогестероном снижает интерферон-продуцирующую функцию эмбриотрофобласта по принципу обратной отрицательной связи. 

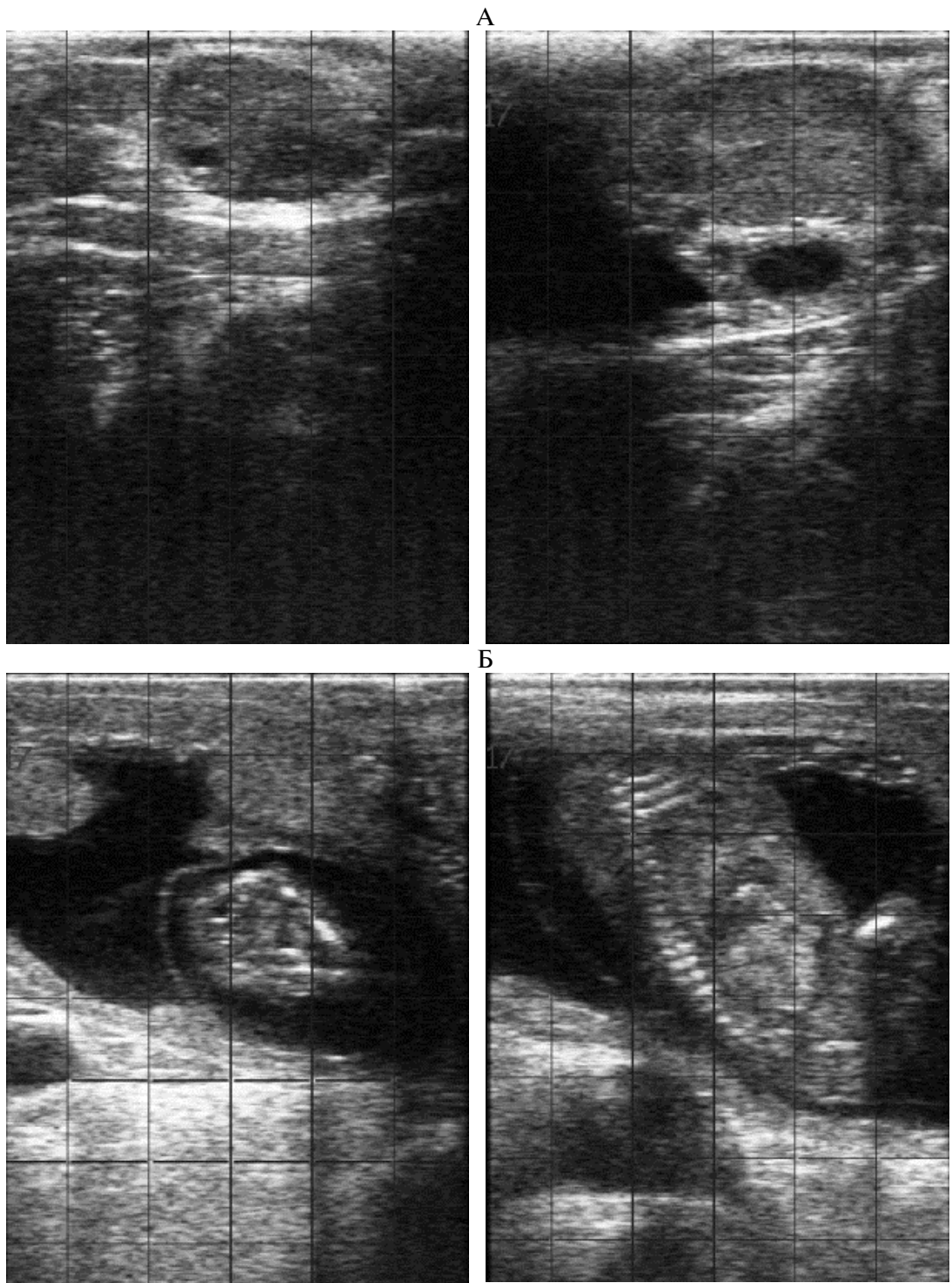

Рис. 1. Желтое тело яичника (А) и эмбрион (Б) у интактных (слева) и обработанных бычьим рекомбинантным интерфероном-tau (справа) коров (Bos taurus taurus) черно-пестрой породы на 60-е сут беременности (СП «Вязноватовка», Нижнедевицкий р-н, Воронежская обл., 2017 год).

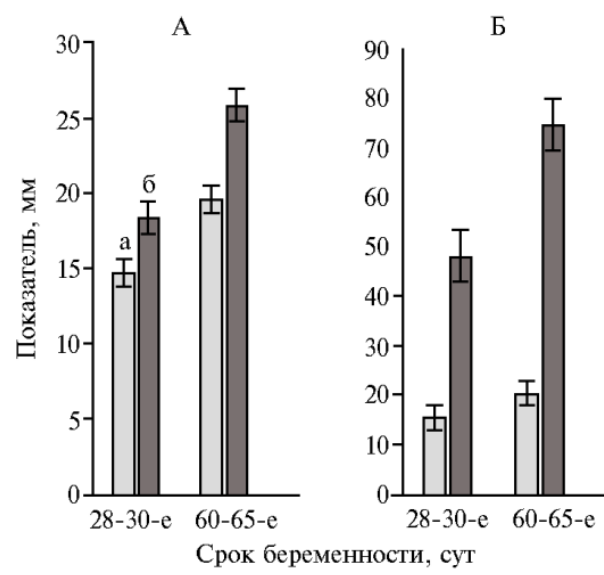

Рис. 2. Диаметр желтого тела яичника (А) и копчико-теменной размер эмбриона и плода (Б) у интактных (а) и обработанных бычьим рекомбинантным интерфероном-tau (б) коров (Bos taurus taurus) черно-пестрой породы в зависимости от срока беременности (СП «Вязноватовка», Нижнедевицкий р-н, Воронежская обл., 2017 год).

Положительное влияние бычьего рекомбинантного INFT на морфофункциональное состояние желтого тела яичника и формирующийся эмбрион и плод подтвердили их метрические показатели при ультразвуковом сканировании (рис. 1, 2). 
Размеры желтого тела яичников у коров в V группе превышали показатели у интактных животных на 28-30-е сут после осеменения на $25,2 \%$ ( $<<0,01)$, на 60-65-е сут - на 32,1\% (p < 0,01). Метрические индексы развивающихся эмбрионов при назначении INFT были выше аналогичных у интактных коров на 28-30-е сут беременности на $32,2 \%$ (p < 0,01), на 60-65-е сут - на 55,3\% (p<0,01).

Оценка иммунного статуса коров до и после введения рекомбинантного INFT показала, что этот интерферон обладает также иммуномодулирующим действием. Об этом свидетельствовали изменения фагоцитарной активности лейкоцитов (ФАЛ), бактерицидной активности сыворотки крови и содержания сывороточных иммуноглобулинов (табл. 3). Через 2 нед после 3-кратных инъекций интерферона ФАЛ возросла на 8,7 \%, фагоцитарное число (ФЧ) - на 35,9 \%, фагоцитарный индекс (ФИ) - на $25,4 \%$. Бактерицидная активность сыворотки крови увеличилась на 5,9 \% $(\mathrm{p}<0,05)$, содержание иммуноглобулинов - на 14,3\% (p < 0,01). У интактных животных подобных изменений не наблюдали. Различия между животными I и V групп по ФАЛ составили 9,3 \% (p < 0,001), ФЧ - 15,2 \%, ФИ - 6,2\%, бактерицидной активности сыворотки $-10,8 \%$ (p < 0,001), содержанию иммуноглобулинов - 18,9\%.

3. Показатели иммунного статуса у интактных и обработанных интерфероном коров (Bos taurus taurus) черно-пестрой породы ( $M \pm \mathrm{SD}$, СП «Вязноватовка», Нижнедевицкий р-н, Воронежская обл., 2017 год)

\begin{tabular}{|c|c|c|c|c|}
\hline \multirow{3}{*}{ Показатель } & \multicolumn{4}{|c|}{ Группа } \\
\hline & \multicolumn{2}{|c|}{ I (отрицательный контроль) } & \multicolumn{2}{|r|}{$\mathrm{V}$} \\
\hline & $\begin{array}{l}\text { перед } \\
\text { введением }\end{array}$ & \begin{tabular}{|l|} 
через 2 нед \\
после введения
\end{tabular} & \begin{tabular}{|l|} 
перед \\
Введением
\end{tabular} & $\begin{array}{l}\text { через } 2 \text { нед } \\
\text { после введения }\end{array}$ \\
\hline ФАЛ, \% & $69,3 \pm 1,2$ & $70,9 \pm 0,8$ & $71,3 \pm 1,5$ & $77,5 \pm 1,0^{* *}$ \\
\hline ФЧ, микробных клет & 4,5 & 4,6 & & $5,3 \pm 0$ \\
\hline ФИ, микробных клеток на актив & $6,5 \pm 0,39$ & $6,5 \pm 0,18$ & $5,5 \pm 0,21$ & $6,9 \pm 0,42^{*}$ \\
\hline Общие иммуноглобулины, г/л & $24,9 \pm 1,5$ & $24,9 \pm 1,4$ & $25,9 \pm 1,1$ & $29,6 \pm 1,5^{* *}$ \\
\hline БАСК, \% & $58,6 \pm 1,2$ & $58,4 \pm 0,7$ & $61,1 \pm 0,8$ & $64,7 \pm 0,8^{*}$ \\
\hline \multicolumn{5}{|c|}{$\begin{array}{l}\text { П р и м е ч а н и е. ФАЛ - фагоцитарная активность лейкоцитов, ФЧ }- \text { фагоцитарное число, ФИ }- \text { фа- } \\
\text { гоцитарный индекс, БАСК - бактерицидная активность сыворотки крови. Описание групп см. в разделе } \\
\text { «Методика». } \\
\text { * и ** Различия относительно фонового значения статистически значимы соответственно при р }<0,05 \text { и } \\
\text { р < }<, 01 .\end{array}$} \\
\hline
\end{tabular}

При рождении масса тела у телят от коров, обработанных INFT, превосходила соответствующий показатель у интактных животных на

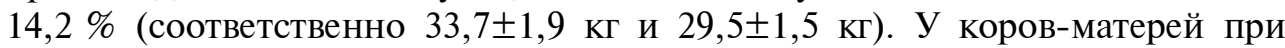
назначении интерферона число послеродовых осложнений снижалось в 1,5 раза.

В совокупности плейотрофные эффекты IFN-tau обеспечивают физиологическое формирование беременности у коров $(16,26)$. Показано, что INFT не только пролонгирует прогестерон-синтезирующую функцию желтого тела, но и совместно с прогестероном обеспечивает синтез и секрецию эндометриального гистиотрофа, включающего аминокислоты, ферменты, глюкозу, цитокины, факторы роста, критически необходимые для питания, имплантации и плацентации эмбриона (27). Однако пороговое значение концентраций INFT в крови у животных, необходимое для поддержания беременности, пока не установлено. В наших опытах в период нидации зародыша они находились в пределах 1090-1200 пг/мл. Гибель эмбриона регистрировали при концентрации 1000-1080 пг/мл. Продолжение исследований по оценке интерферонового статуса животных на ранних сроках гестации, на наш взгляд, позволит предложить нормативный показатель содержания INFT и использовать его в качестве индикатора 
состояния формирующейся беременности. В экспериментах, выполненных на мышах (28), показано также, что экзогенный INFT предупреждает липосахарид-индуцированную имплантационную недостаточность (lipopolysaccharide-induced implantation failure) и увеличивает у таких животных число имплантированных эмбрионов за счет супрессии продукции провосполительных цитокинов (IL-1, TNF).

Таким образом, полученные нами результаты показали, что концентрация INFT в сыворотке крови коров с 7-х по 14-е сут формирования эмбриона возросла на 23,2 \%, а к 35-м сут снизилась на 30,8 \%. При гибели эмбриона концентрация INFT на 14-е сут была ниже на 7,7 \%, на 35 -е сут - на 25,2 \%. Нормальное формирование эмбриона, течение и сохранение беременности у коров в ранние сроки гестации во многом определяются продукцией яичникового прогестерона и трофобластического интерферона-tau как одного из аутокринных регуляторов раннего эмбриогенеза и имплантации. Использованный нами препарат интерферона отвечает заявленным требованиям к биологическим и терапевтическим качествам. Его парэнтеральные инъекции животным в период имплантации зародыша обеспечивают пролонгацию и повышение прогестерон-синтезирующей функции желтого тела яичника на $25,7 \%$, результативности осеменения - на 36,1 \%, снижение проявления синдрома внутриутробной задержки развития плода - на $11,9 \%$, а также увеличение естественной резистентности организма коров-матерей за счет повышения интенсивности фагоцитоза, синтеза сывороточных иммуноглобулинов и бактерицидной активности сыворотки крови. Фармакологический контроль интерферонового, прогестеронового и цитокинового статусов осеменяемых животных в период бластогенеза и имплантации может составлять основу профилактики эмбриональных потерь и повышения фертильности коров в высокопродуктивных молочных стадах.

\section{ЛИТЕРАТУРА}

1. Spencer T.E., Bazer F.W. Biology of progesterone action during pregnancy recognition and maintenance of pregnancy. Front. Biosci., 2002, 7: d1879-d1898 (doi: 10.2741/spencer).

2. Spencer T.E., Burghardt R.C., Johnson G.A., Bazer F.W. Conceptus signals for establishment and maintenance of pregnancy. Animal Reproduction Science, 2004, 82-83: 537-550 (doi: 10.1016/j.anireprosci.2004.04.014).

3. Spencer T.E. Pregnancy recognition and conceptus implantation in domestic ruminants: roles of progesterone, interferon and endogenous retroviruses. Reproduction, Fertility and Development, 2007, 19(1): 65-78 (doi: 10.1071/RD06102).

4. Brooks K., Burns G., Spencer T.E. Conceptus elongation in ruminants: roles of progesterone, prostaglandin, interferon tau and cortisol. Journal of Animal Science and Biotechnology, 2014, 5(1): 53 (doi: 10.1186/2049-1891-5-53).

5. Spencer T.E., Hansen T.R. Implantation and establishment of pregnancy in ruminants. In: Regulation of implantation and establishment of pregnancy in mammals. Advances in anatomy, embryology and cell biology, vol. 216 /R. Geisert, F. Bazer (eds.). Springer, Cham, 2015: 105-135 (doi: 10.1007/978-3-319-15856-3_7).

6. Brooks K., Spencer T.E. Biological roles of interferon tau (IFNT) and type I IFN receptors in elongation of the ovine conceptus. Biology of Reproduction, 2015, 92(2): Article 47 (doi: 10.1095/biolreprod.114.124156).

7. Ealy A.D., Wooldridge L.K. The evolution of interferon-tau. Reproduction, 2017, 154(5): F1F10 (doi: 10.1530/REP-17-0292).

8. Imakawa K., Bai R., Nakamura K., Kusama K. Thirty years of interferon-tau research; past, present and future perspective. Journal of Animal Science and Technology, 2017, 88(7): 927-936 (doi: 10.1111/asj.12807).

9. Godkin J.D., Bazer F.W., Moffatt J., Sessions F., Roberts R.M. Purification and properties of a major, low molecular weight protein releases by the trophoblast of sheep blastocysts at Day 1321. J. Reprod. Fert., 1982, 65(1): 141-150 (doi: 10.1530/jrf.0.0650141).

10. Imakawa K., Anthony R.V., Kazemi M., Marotti K.R., Polites H.G., Roberts R. Interferon like sequence of ovine trophoblast protein secreted by embryonic trophectoderm. Nature, 1987, 
330(6146): 377-379 (doi: 10.1038/330377a0).

11. Demmers R.J., Derecka K., Flint A. Trophoblast interferon and pregnancy. Reproduction, 2001, 121: 41-49.

12. Forde N., Lonergan P. Interferon-tau and fertility in ruminants. Reproduction, 2017, 154(5): F33-F43 (doi: 10.1530/REP-17-0432).

13. Hansen T.R., Sinedino L.D.P., Spencer T.E. Paracrine and endocrine actions of interferon tau (INFT). Reproduction, 2017, 154(5): F45-F59 (doi: 10.1530/REP-17-0315).

14. Zhao G., Jiang K., Zhang T., Wu H., Qiu C., Deng G. Specific interferon tau gene-regulation networks in bovine endometrial luminal epithelial cells. Theriogenology, 2018, 1(105): 51-60 (doi: 10.1016/j.theriogenology.2017.09.004).

15. Basavaraja R., Przygrodzka E., Pawlinski B., Gajewski Z., Kaczmarek M.M., Meidan R. Interferon-tau promotes luteol endothelial cell survival and inhibits specific luteolytic genes in bovine corpus luteum. Reproduction, 2017, 154(5): 559-568 (doi: 10.1530/REP-17-0290).

16. Shirasuna K., Matsumoto H., Matsuyama S., Kimura K., Boliwein H., Miyamoto A. Possible role of interferon tau on the bovine corpus luteum and neutrophils during the early pregnancy. Reproduction, 2015, 150(3): 217-225 (doi: 10.1530/REP-15-0085).

17. Tuo W.B., Macmillan H., Gunter N., Bazer F.M., Brown W.C. Upregulation of interleukin-4 and IFN-gamma expression by IFN-tau, a member of the type I IFN family. Journal of Interferon \& Cytokine Research, 1999, 19(2): 179-187 (doi: 10.1089/107999099314324).

18. Chon T.W., Bixler S. Interferon-tau: current applications and potential in antiviral therapy. Journal of Interferon \& Cytokine Research, 2010, 30(7): 477-485 (doi 10.1089/jiz.2009.0089).

19. Kohara J., Nishikura Y., Konnai S., Tajima M., Onuma M. Effects of interferon-tau on cattle persistently infected with bovine viral diarrhea virus. Japanese Journal of Veterinary Research, 2012, 60(2-3): 63-70.

20. Talukder A.K., Rashid M.B., Yousef M.S., Kusama K., Shimizu T., Shimada M., Suarez S.S., Imakawa K., Miyamoto A. Oviduct epithelium induces interferon-tau in bovine Day-4 embryos, which generates an anti-inflammatory response in immune cells. Scientific Reports, 2018, 8(1): 7850 (doi: 10.1038/s41598-018-26224-8).

21. Rashid M.B., Talukder A.K., Kusama K., Haneda S., Takedomi T., Yoshino H., Moriyasu S., Matsui M., Shimada M., Imakawa K., Miyamoto A. Evidence that interferon-tau secreted from Day-7 embryo in vivo generates anti-inflammatory immune response in the bovine uterus. Biochemical and Biophysical Research Communications, 2018, 500(4): 879-884 (doi: 10.1016/j.bbrc.2018.04.178).

22. Ausubel F.M., Brent R., Kingston R.E., Moore D.D., Seidman J.G., Smith J.A., Struhl K. Current protocols in molecular biology. V. 1. John Wiley\&Sons LTD, NY, 1993.

23. Laemmli U.K. Cleavage of structural proteins during the assembly of the head of bacteriophage T4. Nature, 1970, 227: 680-685 (doi: 10.1038/227680a0).

24. Шахов А.Г., Масьянов Ю.В., Рецкий М.И. и др. Методические рекомендации по оценке иммунного статуса животных. Воронеж, 2005.

25. Kose M., Kaya M.S., Aydilek N., Kucukaslan I., Bayril T., Bademkiran S., Kiyma Z., Ozyurtlu N., Kayis S.A., Guzeloglu A., Atli M.O. Expession profile interferon tau - stimulated genes in ovine peripheral blood leukocytes during embryonic death. Theriogenology, 2016, 85(6): 1161-1166 (doi: 10.1016/j.theriogenology.2015.11.032).

26. Bazer F.W., Thatcher W.W. Chronicling the discovery of interferon tau. Reproduction, 2017, 154(5): F11-F20 (doi: 10.1530/REP-17-0257).

27. Bazer F.W., Ying W., Wang X., Dunlap K.A., Zhou B., Johnson G.A., Wu G. The many faces of interferon tau. Amino Acids, 2015, 47(3): 449-460 (doi: 10.1007/s00726-014-1905-x).

28. Jiang K., Yang J., Chen Y., Guo S., Zhao G., Wu H., Deng G. Protective effects of interferontau against lipopolysaccharide-induced embryo implantation failure in pregnant mice. Journal of Interferon \& Cytokine Research, 2018, 38(5): 226-234 (doi: 10.1089/jir.2017.0126).

1ФГБНУ Всероссийский научно-исследовательский ветеринарный институт патологии, фармакологии u mерапии,

394087 Россия, г. Воронеж, ул. Ломоносова, 114-б, e-mail: svshabunin@rambler.ru $₫$, mikhalevvit@yandex.ru, nadpasko@yandex.ru,vnivipat@mail.ru;

${ }^{2}$ Белорусский государственный университет, 220030 Республика Беларусь, г. Минск, пр. Независимости, 4, e-mail: lysak@bsu.by;

ЗФГБУ Всероссийский государственный

Центр качества и стандартизации лекарственных средств

для животных и кормов,

123022 Россия, г. Москва, Звенигородское ш., 5,

e-mail: asgri1@rambler.ru
Поступила в редакцию 17 июля 2018 года 


\title{
INTERFERON-TAU AND FORMATION OF PREGNANCY IN COWS
}

\author{
S.V. Shabunin', A.G. Nezhdanov', V.I. Mikhalev', N.V. Pasko', V.A. Prokulevich ${ }^{2}$, \\ M.I. Potapovich ${ }^{2}$, V.A. Gricuk ${ }^{3}$, I.V. Volkova ${ }^{1}$
}

${ }^{1}$ All-Russian Research Veterinary Institute of Pathology, Pharmacology and Therapy, 114-b, ul. Lomonosova, Voronezh, 394087 Russia, e-mail svshabunin@rambler.ru ( $₫$ corresponding author), mikhalevvit@yandex.ru, nadpasko@yandex.ru, vnivipat@mail.ru;

2Belarusian State University, 4, pr. Nezavisimosti, Minsk, 220030 Republic of Belarus, e-mail lysak@bsu.by;

${ }^{3}$ Russian State Center for Quality and Standardization of Veterinary Drugs and Feed, 5, Zvenigorodskoe sh., Moscow, 123022 Russia, e-mail asgri1@rambler.ru ORCID:

Shabunin S.V. orcid.org/0000-0002-2689-6998

Nezhdanov A.G. orcid.org/0000-0002-5029-8402

Mikhalev V.I. orcid.org/0000-0001-9684-4045

Pasko N.V. orcid.org/0000-0003-0513-7252

The authors declare no conflict of interests

Received July 17, 2018
Prokulevich V.A. orcid.org/0000-0002-2473-416X

Potapovich M.I. orcid.org/0000-0003-4753-5558

Gricuk V.A. orcid.org/0000-0002-5520-7303

Volkova I.V. orcid.org/0000-0003-3911-7129

doi: 10.15389/agrobiology.2019.2.259eng

\section{Abstract}

Coordinated action of steroid and peptide hormones and interferons ensure the formation of pregnancy and embryo-fetal development in cows. A special class of such interferons is interferontau (INFT) which is synthesized by embryo trophoblast cells. This interferon is responsible for preserving the progesterone synthesis by the ovary yellow body and embryo implantation. This paper is the first in which we report a significance of INFT under impaired embryonic development and data on evaluation of biological and clinical efficacy of bovine recombinant INFT administered to cows after artificial insemination. The aim of this work was to study the dynamics of the blood content of INFT and progesterone $\left(\mathrm{P}_{4}\right)$ during early pregnancy of Black-and-White cows (Bos taurus taurus) and to identify the possibility of using a bovine recombinant INFT preparation to prevent embryonic losses and to increase the effectiveness of insemination. Recombinant INFT was obtained at the Belarusian State University (V.A. Prokulevich, M.I. Potapovich). Blood content of INFT and $\mathrm{P}_{4}$ was determined by ELISA test using Bovine Interferon-Tau Elisa Kit (USA) and Immuno-Fa-PG (Russia) 7, 14, 21 and 35 days after artificial insemination. Animals with physiological formation of embryos $(n$ $=15)$ and with embryonic death $(n=3)$ were tested. The sensitivity of the analyses was $2.9 \mathrm{pg} / \mathrm{ml}$ for INFT and $0.4 \mathrm{nmol} / 1$ for P4. The phagocytic activity of leukocytes, the content of serum immunoglobulins, and the bactericidal activity of blood serum were also determined. The presence/absence of the embryo in the uterus was judged by the concentration of blood progesterone on day 21 and day 35 and by double ultrasound examination on day 35 and day 50. The evaluation of the efficacy of prescribing different doses and schemes of recombinant interferon to increase the effectiveness of insemination and to prevent delayed embryo-fetal development syndrome was carried out on 87 cows. INFT was administered parenterally once, three times, or five times in doses of 5 and $10 \mathrm{ml}$ from day 12 to day 16 after insemination. Intact animals and those subjected to Progestamage administration were used as control groups. It was found that the blood concentration of INFT increased by $23.2 \%$ from day 7 to day 14 , and decreased by $30.8 \%$ on day $35, \mathrm{P}_{4}$ content increased 32 times from day 7 to day 14 of embryo formation. The concentration of INFT was $7.7 \%$ lower on day 14 and $25.2 \%$ lower on day 35 when the embryo died. The blood $\mathrm{P}_{4}$ level of these animals was $26.5 \%$ lower by day 21 and 9.3 times lower by day 35. This suggests that hypointerferonemia and associated hypoprogesteronemia are among the reasons for the delay in the development and death of embryos in the early pregnancy. It was revealed that the optimal scheme of the recombinant INFT use to improve the pregnancy formation in cows is its three-fold parenteral administration in the dose of $5 \mathrm{ml}$ on days 12, 14 and 16 after insemination. As compared to the intact animals, the effectiveness of insemination increased from 38.9 to $75.0 \%$, or by $36.1 \%$, and the delayed embryo-fetal development syndrome decreased from 28.6 to $16.7 \%$, or by $11.9 \%$. Metric indexes of developing embryos exceeded those of the intact animals by $32.2 \%$ on days 28-30 of pregnancy, and by $55.3 \%$ on days 60-65 of pregnancy, and birth weight of the calves was $14.2 \%$ greater. This occurred along with a $33.9 \%$ increase in INFT blood concentration, and 2.3 times increase in $\mathrm{P}_{4}$. Direct replenishment of progesterone deficiency in animals by Progestamage administration provided $38.1 \%$ increase in preservation of pregnancy. It is also shown that INFT preparation has an immunomodulatory effect on the cows. The phagocytic activity of lymphocytes increased by $8.7 \%$, phagocytic number by $35.1 \%$, phagocytic index by $25.1 \%$, bactericidal activity of blood serum increased by $5.9 \%$, and immunoglobulin content by $14.3 \%$ after the INFT triple administration. The conclusion is made about expediency of using the recombinant INFT to increase the fertility of cattle pedigree stock.

Keywords: Bos taurus taurus, cows, blood, interferon-tau, progesterone, early embryogenesis, embryonic death, fertility. 